\title{
Response of physiological parameters in Dionaea muscipula J. Ellis teratomas transformed with ro/B oncogene
}

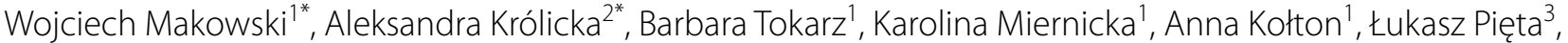 \\ Kamilla Malek ${ }^{3}$, Halina Ekiert ${ }^{4}$, Agnieszka Szopa $^{4}$ and Krzysztof Michał Tokarz ${ }^{{ }^{*}}$
}

\begin{abstract}
Background: Plant transformation with rol oncogenes derived from wild strains of Rhizobium rhizogenes is a popular biotechnology tool. Transformation effects depend on the type of rol gene, expression level, and the number of gene copies incorporated into the plant's genomic DNA. Although rol oncogenes are known as inducers of plant secondary metabolism, little is known about the physiological response of plants subjected to transformation.

Results: In this study, the physiological consequences of ro/B oncogene incorporation into the DNA of Dionaea muscipula J. Ellis was evaluated at the level of primary and secondary metabolism. Examination of the teratoma (transformed shoots) cultures of two different clones ( $K$ and $L$ ) showed two different strategies for dealing with the presence of the ro/B gene. Clone $\mathrm{K}$ showed an increased ratio of free fatty acids to lipids, superoxide dismutase activity, synthesis of the oxidised form of glutathione, and total pool of glutathione and carotenoids, in comparison to nontransformed plants (control). Clone L was characterised by increased accumulation of malondialdehyde, proline, activity of superoxide dismutase and catalase, total pool of glutathione, ratio of reduced form of glutathione to oxidised form, and accumulation of selected phenolic acids. Moreover, clone $L$ had an enhanced ratio of total triglycerides to lipids and accumulated saccharose, fructose, glucose, and tyrosine.
\end{abstract}

Conclusions: This study showed that plant transformation with the ro/B oncogene derived from $R$. rhizogenes induces a pleiotropic effect in plant tissue after transformation. Examination of D. muscipula plant in the context of transformation with wild strains of $R$. rhizogenes can be a new source of knowledge about primary and secondary metabolites in transgenic organisms.

Keywords: Rhizobium rhizogenes, Primary and secondary metabolism, Venus flytrap, Rol genes, Transformation

*Correspondence: wojtek.makowski.1305@gmail.com; aleksandra. krolicka@ug.edu.pl; km.tokarz.jpbb@gmail.com

${ }^{1}$ Department of Botany, Physiology and Plant Protection, Faculty of Biotechnology and Horticulture, University of Agriculture in Krakow, Krakow, Poland

${ }^{2}$ University of Gdansk, Intercollegiate Faculty of Biotechnology UG and MUG, Laboratory of Biologically Active Compounds, Gdansk, Poland Full list of author information is available at the end of the article

\begin{abstract}
Background
Plant transformation with wild strains of Rhizobium rhizogenes (former: Agrobacterium rhizogenes) bacteria has been a popular tool used in biotechnology for decades [1]. This method is based on the natural ability of $R$. rhizogenes to pass a fragment of the $\mathrm{Ri}$ (root-inducing) plasmid and incorporate T-DNA (transfer DNA) into host genomic DNA [2]. Such an event leads to the formation of tumours, hairy roots, or teratomas (transformed shoots) because the expression of bacterial genes in the plant genome disturbs auxin and cytokinin synthesis
\end{abstract}




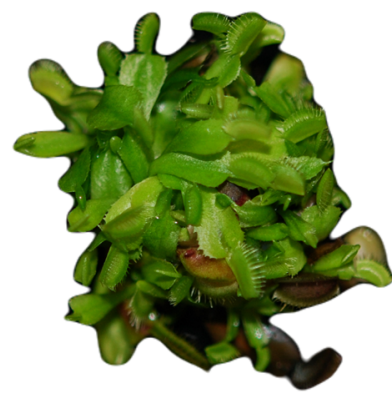

NT plants

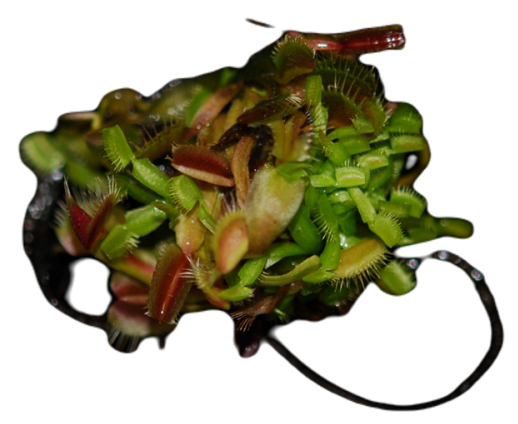

Clone K

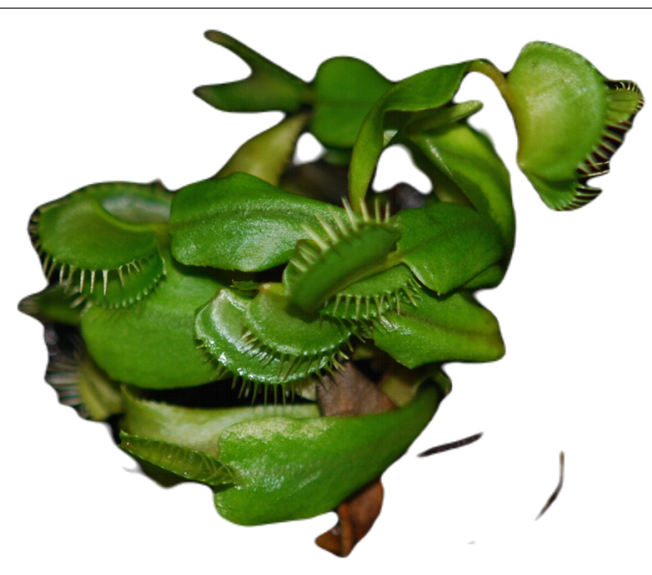

Clone L

Fig. 1 Non-transformed (NT plants) and transformed clones (clones K and L) of Dionaea muscipula plants. Scale bar = $1 \mathrm{~cm}$

pathways, which affects the hormonal balance in plant tissue [3]. Transformed plants are usually characterised by fast growth and long-term genetic and biochemical stability, which makes them a good model in the research and industrial field [2]. In terms of the transformation effects, the most important are oncogenes belonging to the $r o l$ family $(r o l \mathrm{~A}, \operatorname{rol} \mathrm{B}, \operatorname{rol} \mathrm{C}, \operatorname{rol} \mathrm{D})$, which are part of bacterial T-DNA. Although rol genes have been studied for many years, clear knowledge of the complete mechanism of how these genes work is missing [1]. Until now, a few reports have shown possible scenarios of the action of rol genes in plant cells [4-8]. However, the whole picture is still missing.

One of the most popular and useful oncogenes in plant transformation is rolB [9]. This gene is the most powerful inducer of plant secondary metabolism, which is why rolB-transformed plants are models in the medical plant area, as well as in research concentrated on plant secondary metabolism [3]. Expression of the rolB oncogene can increase the level of secondary metabolites in plant tissue $[10,11]$, suppress reactive oxygen species (ROS) production [4], and modulate the antioxidant defence system [8]. Moreover, Veremeichik et al. [12] showed that $r o l \mathrm{~B}$ expression regulates the activity of NADPH oxidase, while Bulgakov et al. [5] reported the tyrosine phosphatase activity of the rolB protein. Nevertheless, the complex physiological response of medical plants transformed with the rolB oncogene has never been studied. To the best of our knowledge, this article is the first report about the response of carnivorous plants to the expression of the $r o l \mathrm{~B}$ gene studied primarily at the level of primary metabolism, and consequently secondary metabolism.
Dionaea muscipula J. Ellis (Venus flytrap), belonging to the Droseraceae family, is an interesting model for research in plant physiology and secondary metabolite production. This unique carnivorous plant is known as a rich source of phenolic compounds, particularly 1,4-naphthoquinone [13]. Because of a huge demand for plant material with a high concentration of phenolic compounds [14], plants from the Droseraceae family have become an important research model in modern plant biotechnology [15]. D. muscipula tissue has a strong biologically active potential $[16,17]$. Additionally, Makowski et al. [11] reported the first genetic transformation of the Venus flytrap with wild strains of $R$. rhizogenes bacteria.

In the present study, we examined two clones (teratomas) of D. muscipula (clones $\mathrm{K}$ and $\mathrm{L}$ ) selected from our previous research. At the molecular level, both plants were transformed with the $r o l \mathrm{~B}$ gene, and it was incorporated into plant genomic DNA in a single copy [11]. Independent of the $R$. rhizogenes strain, such transformation types led to the creation of teratoma (transformed shoots) cultures (Fig. 1). Nevertheless, the results of this research showed that plants differed from each other in terms of growth rate, accumulation of dry matter, and phenolic compound synthesis [11]. Therefore, to understand the differences between clones and to define their response to the rolB gene, it was necessary to examine some physiological parameters in D. muscipula plants.

The main goal of this study was to state the effect of rolB gene on the (I) lipid peroxidation level, (II) synthesis of proline, and (III) enzymatic and non-enzymatic antioxidant system activity in transformed clones of the Venus flytrap. Moreover, using Fourier transform infrared spectroscopy (FTIR), the lipid and sugar metabolism 


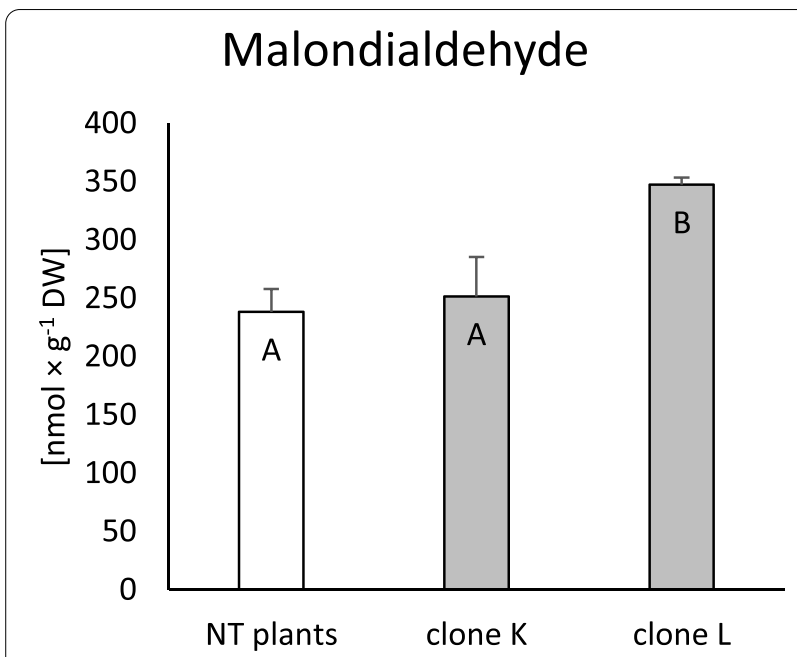

Fig. 2 Accumulation of malondialdehyde (MDA) in non-transformed and transformed tissue of Dionaea muscipula clones. Different letters indicate significant differences between means at $p<0.05$; the bar represents the standard deviation of transformed plants was evaluated for the first time in the context of genetic transformation. We hypothesised that transformation with the rolB oncogene would trigger the complex and pleiotropic effect manifested by changes in redox state, as well as primary and secondary metabolism of examined organisms.

\section{Results}

Accumulation of malondialdehyde (MDA) and proline Membrane integrity was evaluated as the accumulation of MDA, a product of lipid oxidation ROS. Compared to non-transformed (NT) plants, only clone $\mathrm{L}$ accumulated significantly more MDA (46\%), while in clone K, the level of MDA did not change (Fig. 2). Similarly, synthesis of the free amino acid proline only increased in clone L (47\%; Fig. 3).

\section{Enzymatic antioxidant system - activity of peroxidase} (POD), catalase (CAT), and superoxide dismutase (SOD)

In the presented research, the total activity of three antioxidant enzymes was evaluated. Significantly decreased POD activity was found in transformed clone $\mathrm{K}$ tissue, compared to the control. In contrast, CAT was significantly more active (ab. 54\%) in clone L. Moreover, the transformation of $D$. muscipula plants led to increased SOD activity in both examined clones in comparison to NT plants (Table 1).

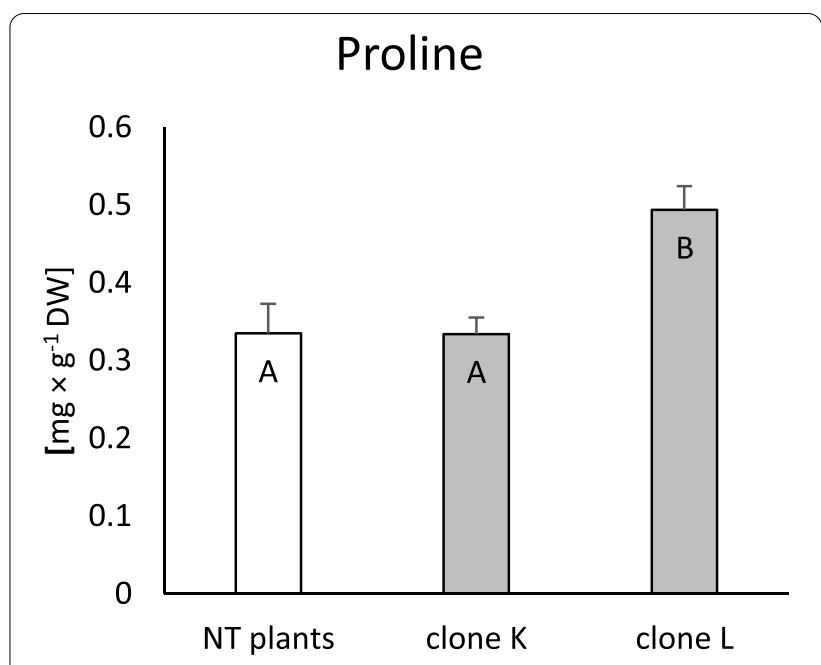

Fig. 3 Accumulation of proline in non-transformed and transformed tissue of Dionaea muscipula clones. Different letters indicate significant differences between means at $p<0.05$; the bar represents the standard deviation

\section{Non-enzymatic antioxidant system}

Total pool of glutathione (GSH + GSSG), reduced (GSH) and oxidised (GSSG) forms, and proportions of reduced and oxidised form (GSH/GSSG)

GSH + GSSG increased significantly in both transformed clones compared to NT plants (Fig. 4c), although individual analysis of GSH and GSSG showed that only the GSSG content increased significantly in clone $\mathrm{K}$ tissue (33\%; Fig. 4a,b). The ratio between the reduced and oxidised forms of glutathione, calculated as the stress indicator, increased significantly in clone $\mathrm{L}$ compared to control plants (Fig. 4d).

\section{Carotenoid content}

One of the important elements of the non-enzymatic antioxidant system in plants is carotenoids. In the

Table 1 Activity of antioxidant enzymes: peroxidase (POD), catalase (CAT) and superoxide dismutase (SOD) in nontransformed and transformed tissue of Dionaea muscipula clones. Different letters in columns - significant differences between means at $p<0.05, \mathrm{SD}-$ standard deviation

\begin{tabular}{llll}
\hline & $\begin{array}{l}\text { POD } \\
{\left[\mathbf{U} \times \mathbf{g}^{-1}\right.} \\
\mathbf{D W} \pm \mathbf{S D}]\end{array}$ & $\begin{array}{l}\text { CAT } \\
{[\boldsymbol{\mu m o l}} \\
\mathbf{H}_{2} \mathbf{O}_{\mathbf{2}} \times \mathbf{m i n}^{-1} \times \mathbf{g}^{-1} \\
\mathbf{D W} \pm \mathbf{S D}]\end{array}$ & $\begin{array}{l}\text { SOD } \\
{\left[\mathbf{U} \times \mathbf{g}^{-1} \mathbf{D W} \pm \mathbf{S D}\right]}\end{array}$ \\
\hline $\begin{array}{l}\text { NT } \\
\text { plants } \\
\text { clone K } \\
\text { clone } \mathrm{L}\end{array}$ & $24.32^{\mathrm{B}} \pm 3.00$ & $527.35^{\mathrm{A}} \pm 151.01$ & $111.22^{\mathrm{A}} \pm 10.25$ \\
& $21.85^{\mathrm{AB}} \pm 0.61$ & $428.76^{\mathrm{A}} \pm 88.81$ & $547.50^{\mathrm{B}} \pm 78.21$ \\
\hline
\end{tabular}




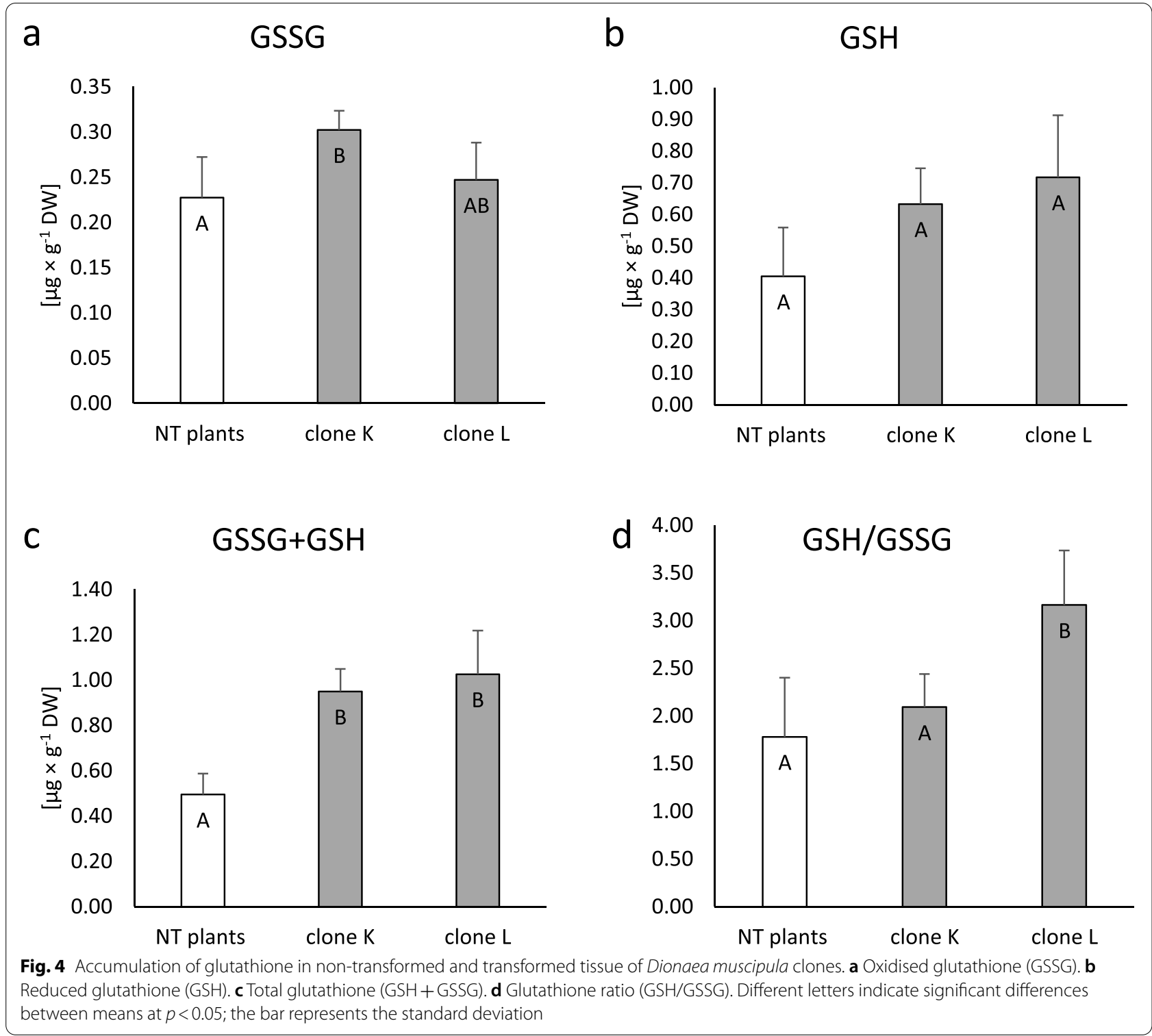

present study, estimation of these pigments showed that both transformed clones of the Venus flytrap synthesised significantly more carotenoids than NT plants. Moreover, clone $\mathrm{K}$ had a significantly higher carotenoid content (26\%) than clone L (Fig. 5).

\section{Phenolic compound accumulation}

Transformation of $D$. muscipula plants significantly affected phenolic compound synthesis. The HPLC-DAD method was used to determine the content of five phenolic acids-chlorogenic acid, p-coumaric acid, ferulic acid, gallic acid, and protocatechuic acid-and one flavonoid-kaempferol-in extracts from transformed and non-transformed plants (Table 2).
The differences were found in the amounts of individual estimated compounds among NT plants and both clones. In NT plants and clone $\mathrm{K}$, the major phenolic compound was kaempferol, except that its accumulation was twice as high in clone tissues (Table 2). In clone L tissues, the main phenolic compounds were gallic acid and ferulic acid (Table 2). In turn, in all examined plants, the minor phenol was p-coumaric acid, although its content differed significantly among tested plants (Table 2). Furthermore, accumulation of protocatechuic acid decreased in both clones in comparison to NT plants, and accumulation of chlorogenic acid increased only in clone $\mathrm{L}$ tissue (Table 2). 


\section{Carotenoids}

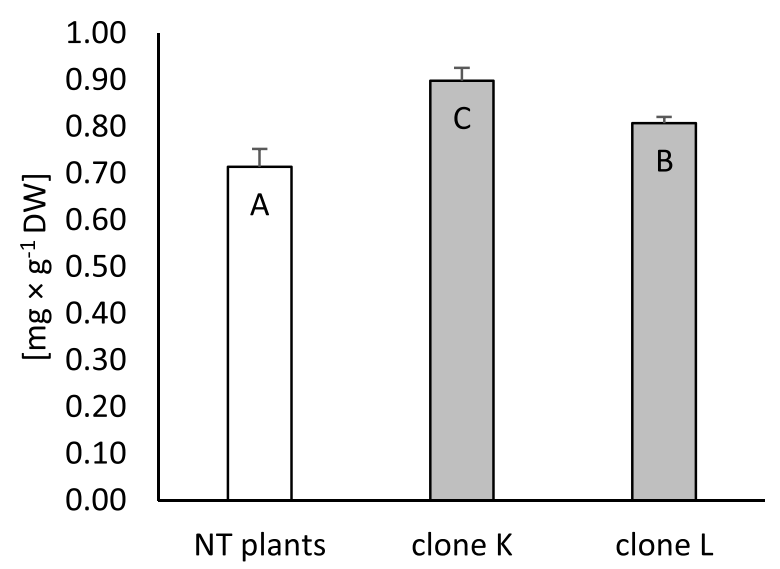

Fig. 5 Accumulation of carotenoids in non-transformed and transformed tissue of Dionaea muscipula clones. Different letters indicate significant differences between means at $p<0.05$; the bar represents the standard deviation

\section{Effect of plant transformation on lipids, sugars, phenolics, and tyrosine}

Spectral lipidomics indicated different changes in the total lipid content (decreased in clone $\mathrm{K}$, increased in clone $\mathrm{L}$ ) and in the contribution of triacyclglycerols and free fatty acids to the lipidic composition (i.e., increased concentrations were determined for clone L and K; Fig. 6a, b, c). Numerous bands below $1200 \mathrm{~cm}^{-1}$ originated from sugars, and the spectral indicators of soluble and insoluble carbohydrates were selected based on reference FTIR spectra [18-20]. The soluble mono- (fructose and glucose) and disaccharides (saccharose) were overproduced only in clone $\mathrm{L}$, in addition to the decomposition of insoluble starch. The control and clone $\mathrm{K}$ contained a similar content of all sugars (Fig. 6d, e, f). All absorbances assigned to the ring modes in the phenyl moieties indicated a significant increase of the phenolic compounds in clone $\mathrm{L}$ (showed for the $1611 \mathrm{~cm}^{-1}$ band only, Fig. $6 \mathrm{~g}$ ). In turn, the intensity of the band attributed to the tyrosine ring vibrations dropped down in the spectrum of clone $\mathrm{K}$ and increased for clone $\mathrm{L}$ compared to the non-transformed plants (Fig. 6h).

\section{Discussion}

D. muscipula is a rich source of phenolic compounds, e.g., flavonoids, phenolic acids, and 1,4-naphthoquinone. That is why this plant can be a suitable model for research on plant secondary metabolism [16]. For this reason, medical plant biotechnology uses genetic transformation with $R$. rhizogenes [2]. The rol gene family, derived from bacterial T-DNA and transferred to the plant genome, can act as an endogenous elicitor of secondary metabolites, allowing study of the production of valuable plantderived chemicals in transformed organisms with stable phenotypes and genotypes [3]. Moreover, Veremeichik et al. [21] showed that the effect of rol gene action on plant metabolism is long-lasting and repeatable. However, little is known about the physiological response of plants to rol oncogene action.

In our previous study, transformation of the Venus flytrap using wild strains of $R$. rhizogenes led to the incorporation of a single copy of the rolB gene into plant DNA [11]. Such transformation occurs due to changes in the plant's growth rate, accumulation of DW, and synthesis of phenolic compounds. Clone $K$ was characterised by a decreased growth rate with simultaneous increased DW content, while clone L grew significantly faster than clone $\mathrm{K}$ and non-transformed plants. Additionally, clone L synthesised an increased amount of various phenolic compounds, which positively affected the antibacterial properties of this clone [11].

The subject of this study was to define how the rolB gene affects $D$. muscipula physiology at the level of oxidative stress response, primary and secondary metabolism, in two clones, $\mathrm{K}$ and L. Tusevki et al. [8] hypothesised that transformation of Hypericum perforatum L. plants with wild strains of $R$. rhizogenes modifies cell redox status and consequently leads to an oxidative stress response. Furthermore, it was demonstrated that the rolB oncogene can suppress

Table 2 Accumulation of phenolic compounds in non-transformed and transformed tissue of Dionaea muscipula clones. Different letters in lines - significant differences between means at $p<0.05$, SD - standard deviation

\begin{tabular}{llll}
\hline $\begin{array}{l}\text { Phenolic compound } \\
{\left[\mathbf{m g} \times \mathbf{1 0 0} \mathbf{~ g}^{-1} \mathbf{D W} \pm \mathbf{S D}\right]}\end{array}$ & NT plants & clone K & clone L \\
\hline gallic acid & & & $53.73^{\mathrm{B}} \pm 0.63$ \\
protocatechic acid & $31.14^{\mathrm{A}} \pm 0.48$ & $28.89^{\mathrm{A}} \pm 1.58$ & $24.20^{\mathrm{A}} \pm 0.57$ \\
chlorogenic acid & $29.12^{\mathrm{B}} \pm 0.63$ & $26.18^{\mathrm{A}} \pm 2.70$ & $28.02^{\mathrm{B}} \pm 0.48$ \\
p-coumaric acid & $20.60^{\mathrm{A}} \pm 0.26$ & $18.83^{\mathrm{A}} \pm 2.54$ & $8.42^{\mathrm{C}} \pm 0.28$ \\
ferulic acid & $4.19^{\mathrm{B}} \pm 1.53$ & $1.09^{\mathrm{A}} \pm 0.14$ & $61.49^{\mathrm{C}} \pm 13.39$ \\
kaempferol & $16.07^{\mathrm{A}} \pm 1.32$ & $39.05^{\mathrm{B}} \pm 0.87$ & $18.30^{\mathrm{A}} \pm 0.37$ \\
\hline
\end{tabular}



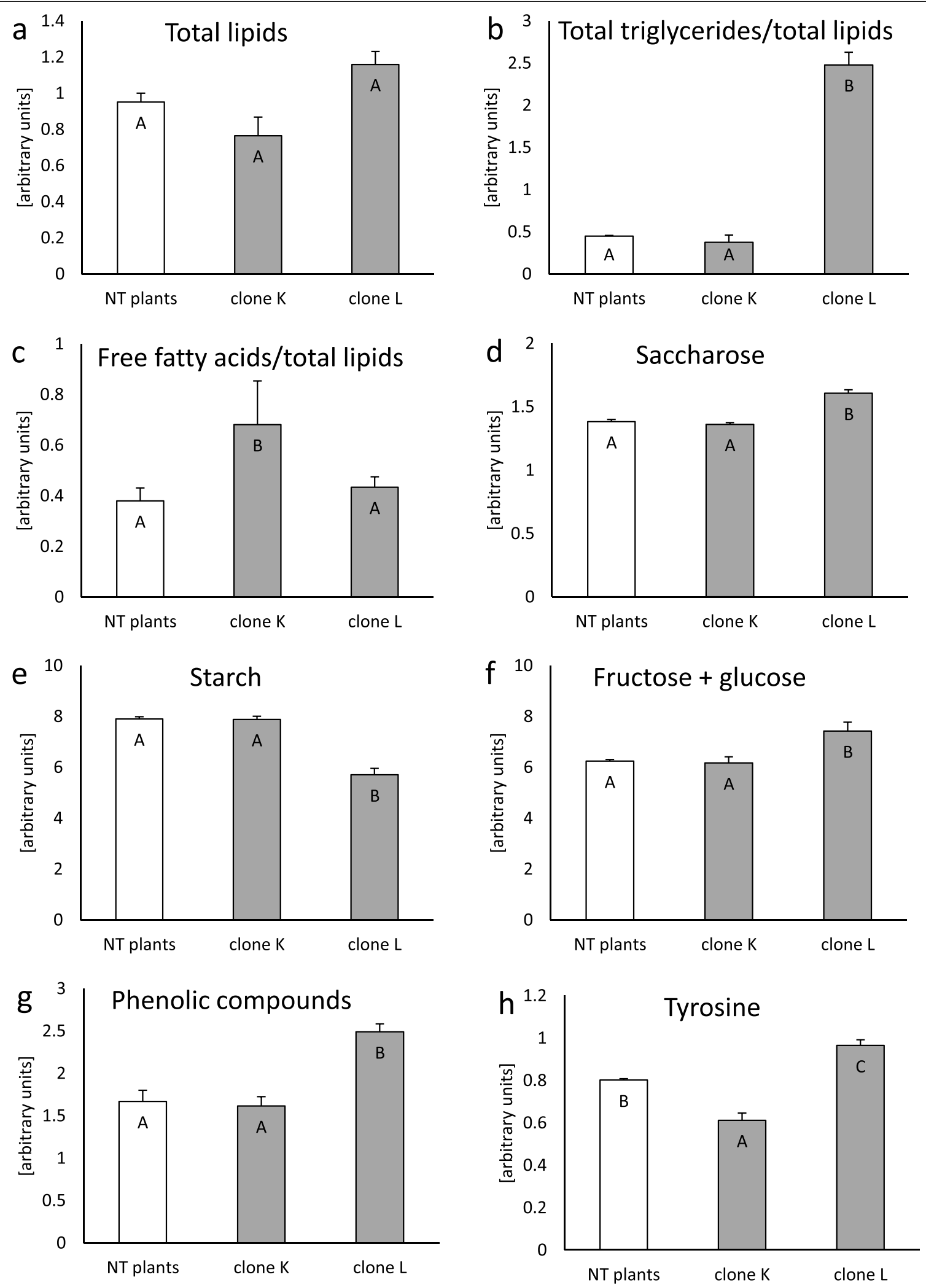

Fig. 6 Semi-quantification biocomponents in non-transformed and transformed tissue of Dionaea muscipula clones, identified in ATR-FTIR spectra. a Total lipids. b Total triglycerides/total lipids. c Free fatty acids/total lipids. $\mathbf{d}$ Saccharose. e Starch. $\mathbf{f}$ Fructose + glucose. $\mathbf{g}$ Phenolic compounds. $\mathbf{h}$ Tyrosine. Different letters indicate significant differences between means at $p<0.05$; the bar represents the standard deviation 
ROS production and activate secondary metabolism in transformed cells, while the mechanism of such an event is still poorly understood [12]. In the present research, MDA content was estimated in transformed plants as the oxidative stress marker. It is well known that an imbalance in ROS production can lead to cell membrane damage, where MDA is a product of lipid peroxidation [22]. Clone $\mathrm{L}$ had increased production of MDA, while clone $\mathrm{K}$ produced MDA on the same level as non-transformed plants (control). According to Franklin et al. [23], MDA synthesis decreased in cells of $H$. perforatum during treatment with Agrobacterium tumefaciens. In contrast, MDA content was increased in $H$. perforatum hairy root lines obtained after transformation with $R$. rhizogenes, compared to non-transformed plants [8]. The upregulation of MDA synthesis in transformed plants may be connected to fast growth in transformed organs and quick development, regardless of the increased activity of antioxidants [8]. Increased mitochondrial respiration during enhanced teratoma development may be a potential donor of huge amounts of ROS, which may lead to lipid-membrane peroxidation [24].

One of the most important elements of plant physiology is the amino acid proline, which is involved in a number of developmental processes, protein synthesis, and stress-related responses, acting as an osmolyte and non-enzymatic antioxidant [25]. Genetic transformation of wheat plants with upregulated proline synthesis and increased tolerance to salt stress was reported by Sawahel and Hassan [26]. Moreover, proline biosynthesis coupled to the pentose phosphate pathway can stimulate the production of phenolics [27]. Tovato et al. [25] discussed the role of proline in the formation of hairy root phenotypes in plants containing the rolD gene after $R$. rhizogenes infection. They postulated that apart from auxins, proline can play an important role in hairy root development and elongation. Transformation of D. muscipula with the rolB gene led to increased production of proline in clone $\mathrm{L}$, while such transformation did not affect the creation of the hairy root phenotype. Accelerated proline synthesis in clone L could be the consequence of the fast growth and demand for primary metabolites, such as proteins in fast teratoma (transformed shoots) development [25]. However, it may be the result of increased oxidative stress in plant tissues, acting as a protectant metabolite in antioxidant defence mechanisms [28].

Oncogenes from $R$. rhizogenes make plant cells more resistant to environmental stress and can inhibit ROS accumulation [7]. The rolB gene can greatly activate secondary metabolism, including the activity of antioxidant proteins CAT, POD, or SOD $[6,21]$. These enzymatic proteins neutralise ROS upon biotic or abiotic stress. Nevertheless, the mechanism by which the rolB gene stimulates the protein antioxidant system remains unknown [8]. Veremeichik et al. [12] showed that the rolB gene regulates the expression of NADPH oxidase in Arabidopsis thaliana and Rubia cordifolia transformed calli, while activity of this enzyme is one of the main sources of ROS production during plant-pathogen interactions. Moreover, it has been postulated that rol genes induce the reprogramming of transformed plant cells and provoke pleiotropic effects on primary and secondary metabolism, including enzymatic and non-enzymatic antioxidant systems [29]. Increased CAT, SOD, and ascorbic peroxidase (APX) activity was reported in transformed hairy roots of $H$. perforatum in comparison to non-transformed plants [8]. Kohsari et al. [30] also showed increased SOD and POD activity in hairy roots of Trigonella foenum-graeceum and Trigonella monantha compared to other organs of these species. Moreover, in $R$. cordifolia callus tissue transformed with the rolB gene, Shkryl et al. [31] demonstrated an increase in total POD activity and enhanced abundance in the transcripts of major POD genes. Interestingly, our study on transformed clones of D. muscipula demonstrated decreased POD activity in the tissue of clone $\mathrm{K}$, with no changes in POD activity in clone $\mathrm{L}$, in comparison to control plants. Furthermore, CAT activity increased in clone L, and SOD activity was enhanced in both examined clones. These findings may be interpreted as the consequence of increased oxidative stress levels in transformed $D$. muscipula clones. SOD is the first defence against ROS in plants, converting superoxide radicals to hydrogen peroxide [32]. Probably, oxidative stress in clone K does not require the increased action of POD and CAT, being on the same level as non-transformed plants. CAT catalyses the decomposition of hydrogen peroxide and only works actively in high hydrogen peroxide concentrations, while lower doses of hydrogen peroxide may be eliminated by POD [29]. The lack of increased POD activity in clone L could be compensation for SOD and CAT activity [8]. However, plant cells try to resist ROS by adjusting the available antioxidant machinery at the right place and time [4].

Another important element of the cellular redox state is a pool of GSSG and GSH, while the GSH/GSSG ratio is known as the oxidative stress indicator [33]. The results showed that clone $\mathrm{K}$ is characterised by an increased pool of GSSG and GSH + GSSG. In turn, clone L has an increased GSH/GSSG ratio and GSH + GSSG. Bulgakov et al. [4] reported that $R$. cordifolia plants transformed with the rolB gene had a slightly increased total pool of glutathione and GSH/GSSG ratio. Moreover, A. thaliana, after transformation, had an enhanced GSH/GSSG 
and increased GSH accumulation. Our results confirmed that $r o l \mathrm{~B}$ oncogene expression may affect redox homeostasis in plant cells, which results not only in the activity of enzymatic antioxidants but also in the production of non-enzymatic antioxidants.

To support this hypothesis, the carotenoid and phenolic acid content of Venus flytrap teratomas was examined, which together with glutathione are an important element of the non-enzymatic antioxidant system in plants [34]. Both examined clones had an increased carotenoid content compared to the control. Moreover, clone $\mathrm{K}$ accumulated more carotenoids than clone L. Furthermore, transformation with the rolB oncogene led to changes in phenolic acid synthesis. Clone $\mathrm{L}$ synthesised more gallic, chlorogenic, and p-coumaric acid than clone $\mathrm{K}$ and control plants. Ferulic acid levels were increased in both clones. Clone $\mathrm{K}$ had the highest kaempferol synthesis, while protocatechuic acid synthesis decreased in both examined clones. These results are in agreement with findings by Makowski et al. [11], where clone L had an increased content of total phenolics and selected phenolic derivatives, while clone $\mathrm{K}$ accumulated phenolic compounds at the same level as control plants, or lower. Furthermore, other authors reported that plant transformation with wild strains of $R$. rhizogenes can lead to increased phenolic acid production $[3,35,36]$. This phenomenon may result from the fact that expression of the rolB gene enhances the activity of phenylalanine ammonia-lyase (PAL) [8]. PAL is a crucial protein in phenolic compound production, catalysing the reaction of trans-cinnamic acid synthesis in plant cells. R. rhizogenes-mediated transformation enhanced $P A L$ expression and stimulated phenylpropanoid metabolism in $H$. perforatum [23]. Simultaneously enhanced growth and increased secondary compound production in response to transformation probably may occurred because of unlimited nutrition resources in vitro conditions. In situations when resources are limited and plants are under stress, a reduction in growth and development may be observed [27].

In the present study, for the first time, the ATR-FTIR technique was combined to estimate some metabolomic parameters in transformed clones of $D$. muscipula. This technique measured lipid, sugar, and protein metabolism changes, demonstrating how the rolB oncogene influences plants' physiology. Lipids are the major components of membranes and have a crucial role in stress signalling in plants [37]. Studying lipid membrane compatibility and composition may show the physiological status of plant cells under stress conditions [38]. Our results showed that plant transformation did not affect the total lipid concentration. Nevertheless, clone L was characterised by an increased triglyceride content in the total lipid content. Furthermore, clone K's response to $r o l \mathrm{~B}$ gene action was manifested by an increased level of free fatty acids. Such changes in lipid compositions following plant transformation may be the result of increased ROS action and lipid oxidation or/and changes in membrane permeability, which enables cellcell communication and transport [39]. Walley et al. [40] reported that modulation of fatty acid metabolism is one of the elements in complex plants' response during the plant-pathogen interaction. Additionally, infection and transformation of plants with $R$. rhizogenes or Rhizobium tumefaciens (former: A. tumefaciens) affect sugar transport and metabolism, while the precise mechanism of action for rol oncogenes in sugar metabolism remains unclear [5]. Potato transformation with the rolC gene from $R$. rhizogenes changed the accumulation pattern of starch, glucose, and dry matter [41]. Grishchenko et al. [42] postulated that rol genes are involved in sugar metabolism through the regulation of enzyme activity, including by glycanases and esterases. These enzymes contribute to the structure of polysaccharides in plant cells. Furthermore, Grishchenko et al. [42] discussed that rather than the rolC gene, rolB expression can modulate the structure of saccharides in cell walls or plastids. Our examinations of transformed $D$. muscipula plants showed that sugar metabolism was affected by the rolB gene only in clone L. Transformation of this clone led to decreased accumulation of starch with simultaneously increased levels of soluble sugars: saccharose and the sum of fructose and glucose. This may be a consequence of faster primary metabolism in clone L. In our previous findings, this clone was characterised by an enhanced growth rate [11]. In such a scenario, the plant needs simple sugars for primary processes and development [43]. It can also be postulated that increased accumulation of simple sugars is connected with oxidative stress in clone L teratomas [44]. In addition to the role in plant growth and development, sugars play a crucial role in signalling cross-talk during the response to environmental stress [44].

Analysis of FTIR spectra also confirmed our findings about phenolic compound accumulation in clones $\mathrm{K}$ and L. In our previous paper, teratomas of clone $\mathrm{L}$ accumulated an increased quantity of phenolic compounds [11]. In this article, the same trend was observed for phenolic acids evaluated with HPLC. Using a very sensitive technique, FTIR, it was demonstrated that clone $\mathrm{L}$ accumulated more phenolic compounds than the control and clone $\mathrm{K}$.

In the context of plant transformation, the synthesis of tyrosine is an important element. In contrast, this aromatic amino acid is the product of primary metabolism. 
It is used as the precursor for phenolic compound synthesis in the first step of the phenylpropanoid pathway [28]. However, it is postulated that the rolB oncogene encodes proteins with tyrosine phosphatase activity, which is crucial in the oncogenesis process [9]. Clone $\mathrm{L}$ had an increased accumulation of tyrosine, while the level of this amino acid decreased in clone $\mathrm{K}$. This corresponds with the hypothesis of Bulgakov [9] that the tyrosine phosphatase function of the rolB gene enhances secondary metabolism, while dephosphorylation of tyrosine in proteins is an element of the pleiotropic effect of the rolB oncogene in plant cells.

\section{Conclusions}

Transformed plants of $D$. muscipula are a new source of knowledge about the physiology of transgenic organisms. Examination of two clones, $\mathrm{K}$ and $\mathrm{L}$, showed differences in the response of these plants to transformation events, although both were transformed with a single copy of the rolB gene. The pleiotropic effect of the rolB gene in transformed plants may be manifested by the regulation of primary and secondary metabolism. The example of clone $\mathrm{L}$ showed that transformation with $R$. rhizogenes may lead to enhanced primary and secondary metabolism, as well as promotion of the antioxidant system. Analysis of clone $\mathrm{K}$ showed that incorporation of the rolB gene in plant genomic DNA does not always cause significant physiological changes. Understanding the mechanisms involved in plant responses to transformation with the rolB gene needs further research.

\section{Methods}

\section{Plant material}

In this study, the plant materials were two transformed clones (teratomas) of D. muscipula. Plants were transformed with two wild $R$. rhizogenes strains: LBA 9402 (clone K) and ATCC 15834 (clone L; Fig. 1). Plant transformation and selection process, as well as molecular confirmation of transformation, were described by Makowski et al. [11].

For this research, non-transformed plants (NT plants) and transformed clones were cultivated using in vitro conditions [17]. Briefly, plants were grown in liquid $1 / 2$ strength Murashige and Skoog medium (1/2 MS) [45] with no growth regulators, $3 \%$ sucrose, and $\mathrm{pH}=5.5$ (adjusted prior to autoclaving), with rotary shaking (130 rpm). Plants were cultivated at a temperature of $23 \pm 1{ }^{\circ} \mathrm{C}$, in fluorescence light at $80 \times \mathrm{mol} \times \mathrm{m}^{2} \times \mathrm{s}^{1}$ photosynthetic photon flux density (PPFD) and a photoperiod of $16 \mathrm{~h} / 8 \mathrm{~h}$ light/dark cycle. NT plants and transformed teratomas of both clones were cultivated in 10 biological repetitions.
Sixty-day-old tissue cultures were harvested, freeze-dried for $72 \mathrm{~h}$, and homogenised for further analysis.

\section{MDA content estimation}

MDA levels were estimated according to Dhindsa et al. [46], with modifications [47]. Plant tissue was extracted in $1 \mathrm{ml}$ of $0.1 \%$ trichloroacetic acid (TCA) solution at $4{ }^{\circ} \mathrm{C}$ and centrifuged for $15 \mathrm{~min}$ at $25155 \times \mathrm{g}$. Subsequently, $0.2 \mathrm{ml}$ of the obtained supernatant was mixed with $0.8 \mathrm{ml}$ of $20 \%$ TCA and $0.5 \%$ thiobarbituric acid (TBA). Samples were incubated at $95^{\circ} \mathrm{C}$ for $30 \mathrm{~min}$ and centrifuged for $10 \mathrm{~min}$ at $25155 \times \mathrm{g}$. The absorbance of mixtures was measured at 532 and $600 \mathrm{~nm}$. Each spectrophotometric analysis in this study was done using a double beam spectrophotometer U-2900 (Hitachi High-Technologies Corporation, Tokyo, Japan). The content of MDA was calculated using the absorbance coefficient for MDA $\left(\varepsilon=155 \mathrm{mM} \mathrm{cm}^{-1}\right)$ after reduction of the value at $532 \mathrm{~nm}$ by the correction value at $600 \mathrm{~nm}$. The results were expressed as nM MDA per $1 \mathrm{~g}$ of DW tissue.

\section{Proline content}

Accumulation of proline in plant tissue was measured according to Bates et al. [48], with modifications [49]. Dry plant tissue was homogenised in $1 \mathrm{~mL} 3 \%$ aqueous solution of sulfosalicylic acid at $4{ }^{\circ} \mathrm{C}$. Extracts were centrifuged for $15 \mathrm{~min}$, and $0.5 \mathrm{~mL}$ was mixed with $0.5 \mathrm{ml}$ acid ninhydrin and $0.5 \mathrm{ml}$ glacial acetic acid. Samples were incubated for $1 \mathrm{~h}$ at $100^{\circ} \mathrm{C}$, and the reaction was stopped on ice. Toluene $(1 \mathrm{ml})$ was used to extract the reaction mixture. Absorbance was measured at $520 \mathrm{~nm}$, and the proline concentration was determined from a calibration curve. Calibrations were made with L-proline (Sigma-Aldrich Chemie, GmBH, Steinheim, Germany) as the standard. The results were expressed as $\mathrm{mg}$ of proline per $1 \mathrm{~g}$ of DW tissue.

\section{Antioxidant enzyme activity}

To estimate the CAT, POD, and SOD activity, native proteins were extracted from dry plant material $(20 \mathrm{mg})$ using $2 \mathrm{~mL}$ potassium phosphate buffer $(0.05 \mathrm{M}$, $\mathrm{pH}=7.00)$ at $4^{\circ} \mathrm{C}$. The samples were centrifuged for $15 \mathrm{~min}$ at $25155 \times \mathrm{g}\left(4^{\circ} \mathrm{C}\right)$. The obtained supernatant was collected for protein content estimation and analysis of enzyme activity. All measurements were performed using a double beam spectrophotometer U-2900 (Hitachi High-Technologies Corporation, Tokyo, Japan).

The protein concentration in the extract was determined using the Bradford reagent and bovine serum albumin (BSA) as a standard [50]. CAT activity was determined using the method described by Aebi [51] with modifications by Tokarz et al. [52]. The supernatant $(0.2 \mathrm{~mL})$ was mixed with $1.8 \mathrm{~mL}$ phosphate buffer $(\mathrm{pH} 7.0)$ 
and $1 \mathrm{~mL} \mathrm{H}_{2} \mathrm{O}_{2}$ solution in phosphate buffer. The absorbance of $\mathrm{H}_{2} \mathrm{O}_{2}$ decomposed by the enzyme was measured at $240 \mathrm{~nm}$ for $4 \mathrm{~min}$ in 1-min intervals. The results were presented as the amount of enzyme that decomposed $1 \mu \mathrm{mol} \mathrm{H}_{2} \mathrm{O}_{2}$ in $1 \mathrm{~min}$.

The POD activity was determined using the spectrophotometric method by Lück [53], with modifications by Tokarz et al. [52]. This method was based on the reaction of p-phenyldiamine oxidation to phenazine by the tested enzyme. Phosphate buffer (1.5 mL; pH 6.2), supernatant $(0.5 \mathrm{~mL})$, and $1 \%$ p-phenyldiamine solution $(0.1 \mathrm{~mL})$ was mixed with $0.1 \mathrm{~mL} 0.1 \% \mathrm{H}_{2} \mathrm{O}_{2}$. The absorbance was measured at $485 \mathrm{~nm}$ (0.1 rise of absorbance correspond to one unit of POD activity).

SOD activity was measured according to Hwang et al. [54], with modifications [34]. The enzyme extract was mixed with methionine, nitro blue tetrazolium, and riboflavin. The mixture was incubated in light (two $18 \mathrm{~W}$ fluorescence lamps). Absorbance was measured at $560 \mathrm{~nm}$ after 5 and $10 \mathrm{~min}$. A similar mixture without the enzyme was prepared as a control, in which the reaction efficiency reached $100 \%$. One unit of enzyme activity was defined as $50 \%$ inhibition of the reaction.

\section{Non-enzymatic antioxidants Carotenoid accumulation}

The dried sample $(20 \mathrm{mg})$ was extracted three times in $1 \mathrm{~mL} 80 \%$ acetone with the addition of $\mathrm{MgCl}_{2}$ to discolour plant tissue at $4{ }^{\circ} \mathrm{C}$ [55]. The samples were centrifuged for $15 \mathrm{~min}$ at $25155 \times \mathrm{g}\left(4^{\circ} \mathrm{C}\right)$. The absorbance of the diluted supernatant was measured at $470 \mathrm{~nm}$ using a double beam spectrophotometer U-2900 (Hitachi HighTechnologies Corporation, Tokyo, Japan). The carotenoid content was calculated according to Wellburn [56].

\section{Reduced and oxidised glutathione}

The glutathione pool was measured according to Queval and Noctor [57], where 5,5-dithiobis(2-nitro-benzoic acid) (DTNB) is glutathione reductase (GR)-dependent reduced. DW tissue $(20 \mathrm{mg})$ was extracted at $4{ }^{\circ} \mathrm{C}$ using $1 \mathrm{~mL} 0.2 \mathrm{~N} \mathrm{HCl}$. The samples were centrifuged at $25255 \times g$ for $10 \mathrm{~min}$ at $4^{\circ} \mathrm{C}$. The obtained supernatant $(0.5 \mathrm{~mL})$ was neutralised with $0.5 \mathrm{M} \mathrm{NaOH}$ in the presence of $50 \mu \mathrm{L} 0.2 \mathrm{M} \mathrm{NaH}_{2} \mathrm{PO}_{4}(\mathrm{pH} 5.6)$ to reach a final $\mathrm{pH}$ between 5 and 6 . The method allowed the measurement of the total glutathione pool (reduced plus oxidised form: GSSG+GSH) and, after pre-treatment of the extract aliquots with 2-vinylpyridine (VPD), only GSSG was measured. To measure GSSG+GSH, aliquots of $30 \mu \mathrm{L}$ neutralised extracts were added to $300 \mu \mathrm{L} 0.2 \mathrm{M}$ $\mathrm{NaH}_{2} \mathrm{PO}_{4}$ (pH7.5), $30 \mu \mathrm{L} 10 \mathrm{mM}$ EDTA, $30 \mu \mathrm{L} 10 \mathrm{mM}$ $\mathrm{NADPH}, 30 \mu \mathrm{L} 12 \mathrm{mM}$ DTNB, and $180 \mu \mathrm{L}$ distilled water. The reaction was started by the addition of $30 \mu \mathrm{L}$ GR $\left(20 \mathrm{UmL}^{-1}\right)$, and the increase in the absorbance at $412 \mathrm{~nm}$ was monitored for $2 \mathrm{~min}$. The GSSG fraction was measured using the same routine after incubation of $200 \mu \mathrm{L}$ neutralised extract with $3 \mu \mathrm{L}$ VPD for $30 \mathrm{~min}$ at room temperature to complex GSH. Calculations were made on the basis of standard curves plotted simultaneously for GSH and GSSG. The GSH/GSSG ratio was also calculated.

\section{Phenolic compound estimation using DAD-HPLC}

The phenolic compounds were estimated in methanolic extracts prepared from $200 \mathrm{mg}$ DW tissue in $2.5 \mathrm{~mL}$ HPLC-grade methanol using sonication (two times for $30 \mathrm{~min}$ at $25 \pm 2{ }^{\circ} \mathrm{C}$ ) (Polsonic). Samples were centrifuged $\left(25,255 \times g\right.$ for $15 \mathrm{~min}$ at $\left.4^{\circ} \mathrm{C}\right)$. The obtained supernatant was filtered through syringe filters $\left(0.22 \mu \mathrm{m}\right.$ Millex ${ }^{\circledR} \mathrm{GP}$, Millipore, Merck, Darmstadt, Germany) for analysis with high pressure liquid chromatography with a diode array detector (DAD-HPLC).

The quantitative analyses of phenolic compounds in the extracts were done by a validated method, using an apparatus from Merck-Hitachi (LaChrom Elite) with a DAD L-2455 detector and a Purospher RP-18 $(250 \times 4 \mathrm{~mm}$; $5 \mu \mathrm{m}$, Merck, Germany) column [58, 59]. The flow rate was $1 \mathrm{~mL} \times \min ^{-1}$, and temperature was set at $25^{\circ} \mathrm{C}$; the injection volume was $10 \mu \mathrm{L}$. The detection wavelength was set at $254 \mathrm{~nm}$. The mobile phase consisted of Amethanol, $0.5 \%$ acetic acid $1: 4$ and $\mathrm{B}-$ methanol $(\mathrm{v} / \mathrm{v})$. The gradient program was as follows: $0-20 \mathrm{~min}, 0 \% \mathrm{~B}$, 20-35 min, 0-20\% B, 35-45 min, 20-30\% B, 45-55 min, $30-40 \%$ B, 55-60 min, 40-50\% B, 60-65 min, 50-75\% B, and $65-70 \mathrm{~min}, 75-100 \% \mathrm{~B}$, with a hold time of $15 \mathrm{~min}$. Identification was performed by comparison to retention times and UV spectra of standards (chlorogenic acid, p-coumaric acid, ferulic acid, gallic acid, protocatechuic acid, and kaempferol acquired from Sigma-Aldrich Co., Germany). The quantification was performed based on the calibration curves method. Samples were prepared and analysed in five replications. The results were expressed in $\mathrm{mg} \times 100 \mathrm{~g}^{-1} \mathrm{DW} \pm \mathrm{SD}$.

\section{ATR-FTIR measurements}

Various plant organics absorb the mid-infrared light, giving a molecular fingerprint to the chemical composition when examined in the $4000-900 \mathrm{~cm}^{-1}$ region. In our study label-free and rapid FTIR spectroscopy with attenuated total reflection mode (ATR) was used to determine changes in plant tissue composition after transformation with wild $R$. rhizogenes bacteria. Analysis revealed the presence of various characteristic functional groups originating from lipids, phenolic compounds, and a plethora 
of mono- and polysaccharides (see Additional file 1). Amide I and II bands of proteins were absent. There was an alternation of intensities in IR bands assigned to lipids (stretches of the $\mathrm{CH}_{2}$ groups; $2850 \mathrm{~cm}^{-1}$ ), triglycerides (stretches of the ester $\mathrm{C}=\mathrm{O}$ groups; $1735 \mathrm{~cm}^{-1}$ ), fatty acids (stretches of the acidic $\mathrm{C}=\mathrm{O}$ groups $1718 \mathrm{~cm}^{-1}$ ), sugars (stretches and deformations of the $\mathrm{C}-\mathrm{C}$ and $\mathrm{C}-\mathrm{O}$ groups; saccharose $-866 \mathrm{~cm}^{-1}$; starch $-1154 / 1076 \mathrm{~cm}^{-1}$; fructose and glucose-1104/1020 $\mathrm{cm}^{-1}$ ), phenolic compounds (stretches of the $\mathrm{C}=\mathrm{C}$ groups; $1611 \mathrm{~cm}^{-1}$ ), and tyrosine residues (stretches of the $\mathrm{C}=\mathrm{C}$ groups $1511 \mathrm{~cm}^{-1}$ ). Their values are the estimate of the content of molecules $[18,19]$.

Ground, freeze-dried leaves and stems were deposited on an ATR crystal. ATR-FTIR spectra were recorded with a Bruker Alpha FTIR spectrometer with a singlebounce diamond ATR crystal. For each sample, at least three spectra were acquired with a spectral resolution of $4 \mathrm{~cm}^{-1}$ in the region of 4000 to $600 \mathrm{~cm}^{-1}$ by coadding 64 scans. Spectra pre-processing and analysis were performed using OPUS software (Bruker Optics, Bullerica, MA, USA, Version 7.2.139.1294). First, the extended ATR correction was applied as implemented in the software. After vector normalisation in the region of $3700-600 \mathrm{~cm}^{-1}$, the second derivative IR spectra were calculated with 9 smoothing points according to a Savitzky-Golay protocol. Second derivative/absorption spectra were used for the calculation of the integral intensity of various bands. For this purpose, a linear baseline was drawn through the peak edges, and the spectrum below this line was integrated over the wavenumber range of the band. For the comparison of spectral differences between studied groups, spectra from each measurement were averaged within the sample.

\section{Statistical analyses}

Statistical analyses were performed using STATISTICA 12.0 (StatSoft Inc., Tulsa, OK, USA). The results were subjected to one-way analysis of variance (ANOVA), and the significance of differences between the arithmetical means was determined by Tukey's post hoc test at $p \leq 0.05$.

\footnotetext{
Abbreviations

ROS: Reactive oxygen species; T-DNA: Transfer DNA; FTIR: Fourier transform infrared spectroscopy; DW: Dry weight; MDA: Malondialdehyde; POD: Peroxidase; CAT: Catalase; SOD: Superoxide dismutase; GSH: Reduced form of glutathione; GSSG: Oxidised form of glutathione; NT plants: Non-transformed plants; APX: Ascorbic peroxidase; PAL: Phenylalanine ammonia lyase; TCA :Trichloroacetic acid; TBA: Thiobarbituric acid; DTNB: 5,5-dithiobis(2-nitrobenzoic acid); BSA: Bovine serum albumin; PPFD: Photosynthetic photon flux density.
}

\section{Supplementary Information}

The online version contains supplementary material available at https://doi. org/10.1186/s12870-021-03320-y.

Additional file 1: Averaged ATR-FTIR spectra (a) and their second derivatives $(\mathbf{b})( \pm \mathrm{SD})$ of non-transformed and transformed tissue of Dionaea muscipula clones.

\section{Acknowledgements}

The paper benefited greatly from the comments received from two anonymous reviewers.

\section{Authors' contributions}

WM, AKr, and KMT: conception and experiment design; WM: performed all spectrophotometric and statistical analysis, interpreted the data, prepared the graphical part of the manuscript, and wrote the manuscript; BT and KMi: contributed to data acquisition; AKo: developed the analytical method for estimation of the glutathione pool and superoxide dismutase activity; ŁP and KMa: performed ATR-FTIR analysis; ASz and HE: performed the HPLC analysis; WM, AKr, KMT, and BT: checked and corrected the manuscript. All authors proofread the manuscript, agreed on its contents, and consented to its submission. The author(s) read and approved the final manuscript.

\section{Funding}

This study was funded by the National Science Centre, Poland (grant number 2018/31/N/NZ9/00581).

\section{Availability of data and materials}

The datasets used and/or analysed during the current study are available from the corresponding author upon reasonable request.

\section{Declarations}

Ethics approval and consent to participate

Our research did not involve any human or animal subjects, material, or data. The plant materials used in this study came from the collection of in vitro cultures of the Laboratory of Biologically Active Compounds, Intercollegiate Faculty of Biotechnology UG and MUG, University of Gdansk, Poland.

\section{Consent for publication}

Not applicable.

\section{Competing interests}

The authors declare that they have no competing interests.

\section{Author details}

${ }^{1}$ Department of Botany, Physiology and Plant Protection, Faculty of Biotechnology and Horticulture, University of Agriculture in Krakow, Krakow, Poland. ${ }^{2}$ University of Gdansk, Intercollegiate Faculty of Biotechnology UG and MUG, Laboratory of Biologically Active Compounds, Gdansk, Poland. ${ }^{3}$ Jagiellonian University in Krakow, Faculty of Chemistry, Krakow, Poland. ${ }^{4}$ Department of Pharmaceutical Botany, Jagiellonian University, Medical College, Krakow, Poland.

Received: 16 July 2021 Accepted: 5 November 2021 Published online: 29 November 2021

References

1. Mauro ML, Costantino P, Bettini PP. The never ending story of ro/ genes: a century after. Plant Cell Tissue Organ Cult 2017;131:201-212. 
2. Matveeva TV, Sokornova SV, Lutova LA. Influence of Agrobacterium oncogenes on secondary metabolism of plants. Phytochem Rev. 2015;14:541-54

3. Tusevski O, Vinterhalter B, Milošević DK, Soković M, Ćirić A, Vinterhalter D, et al. Production of phenolic compounds, antioxidant and antimicrobial activities in hairy root and shoot cultures of Hypericum perforatum L. Plant Cell Tissue Organ Cult. 2017;128:589-605.

4. Bulgakov VP, Gorpenchenko TY, Veremeichik GN, Shkryl YN, Tchernoded GK, Bulgakov DV, et al. The rolB gene suppresses reactive oxygen species in transformed plant cells through the sustained activation of antioxidant defense. Plant Physiol. 2012;158:1371-81.

5. Bulgakov VP, Shkryl YN, Veremeichik GN, Gorpenchenko TY, Vereshchagina YV. In: Doran PM, editor. Biotechnology of hairy root systems. Heidelberg New York Dordrecht London: Springer; 2013. p. 1-22.

6. Bulgakov VP, Veremeichik GN, Grigorchuk VP, Rybin VG, Shkryl YN. The ro/B gene activates secondary metabolism in Arabidopsis calli via selective activation of genes encoding MYB and $\mathrm{bHLH}$ transcription factors. Plant Physiol Biochem. 2016;102:70-9.

7. Bulgakov VP, Vereshchagina YV, Bulgakov DV, Veremeichik GN, Shkryl YN. The rolB plant oncogene affects multiple signaling protein modules related to hormone signaling and plant defense. Sci Rep. 2018;8:2285. https://doi.org/10.1038/s41598-018-20694-6.

8. Tusevski O, Petreska Stanoeva J, Stefova M, Spasenoski M, Gadzovska Simic S. State of antioxidant systems and phenolic compounds' production in Hypericum perforatum L hairy roots. Acta Physiol Plant. 2019;41:132. https://doi.org/10.1007/s11738-019-2919-5.

9. Bulgakov VP. Functions of rol genes in plant secondary metabolism. Biotechnol Adv. 2008;26:318-24.

10. Matvieieva NA, Morgun BV, Lakhneko OR, Duplij VP, Shakhovsky AM, Ratushnyak Yl, et al. Agrobacterium rhizogenes-mediated transformation enhances the antioxidant potential of Artemisia tilesii Ledeb. Plant Physiol Biochem. 2020;152:177-83.

11. Makowski W, Królicka A, Nowicka A, Zwyrtková J, Pecinka A, Banasiuk R, et al. Transformed tissue of Dionaea muscipula J. Ellis as a source of biologically active phenolic compounds with bactericidal properties. Appl Microbiol Biotechnol. 2021;105:1215-26.

12. Veremeichik G, Bulgakov V, Shkryl Y. Modulation of NADPH-oxidase gene expression in rolB-transformed calli of Arabidopsis thaliana and Rubia cordifolia. Plant Physiol Biochem. 2016;105:282-9.

13. Gaascht F, Dicato M, Diederich M. Venus flytrap (Dionaea muscipula Solander ex Ellis) contains powerful compounds that prevent and cure cancer. Front Oncol. 2013;3:202. https://doi.org/10.3389/fonc.2013.00202.

14. Canter $\mathrm{PH}$, Thomas $\mathrm{H}$, Ernst E. Bringing medicinal plants into cultivation: opportunities and challenges for biotechnology. Trends Biotechnol. 2005;23(4):180-5.

15. Królicka A, Szpitter A, Stawujak K, Barański R, Gwizdek-Wiśniewska A, Skrzypczak A, et al. Teratomas of Drosera capensis var. alba as a source of naphthoquinone: ramentaceone. Plant Cell Tissue Organ Cult. 2010:103:285-92.

16. Królicka A, Szpitter A, Gilgenast E, Romanik G, Kaminski M, Lojkowska E. Stimulation of antibacterial naphthoquinones and flavonoids accumulation in carnivorous plants by addition of elicitors. Enzym Microb Technol. 2008:42:216-21.

17. Makowski W, Tokarz KM, Tokarz B, Banasiuk R, Witek K, Królicka A. Elicitation-based method for increasing the production of antioxidant and bactericidal phenolic compounds in Dionaea muscipula. J Ellis Tissue Molecules. 2020;25:1794. https://doi.org/10.3390/molecules25081794.

18. Trivedi MK, Branton A, Trivedi D, Shettigar H, Bairwa K, Snehasis J. Fourier transform infrared and ultraviolet-visible spectroscopic characterization of biofield treated salicylic acid and sparfloxacin. Nat Prod Chem Res. 2015;3:5. https://doi.org/10.4172/2329-6836.1000186.

19. Johnson J, Mani J, Ashwath N, Naiker M. Potential for Fourier transform infrared (FTIR) spectroscopy toward predicting antioxidant and phenolic contents in powdered plant matrices. Spectrochim Acta A Mol Biomol Spectrosc 2020;233:118228 (doi: https://doi.org/10.1016/j.saa.2020. 118228).

20. Wiercigroch E, Szafraniec E, Czamara K, Pacia MZ, Majzner K, Kochan K, et al. Raman and infrared spectroscopy of carbohydrates: a review. Spectrochim Acta A Mol Biomol Spectrosc. 2017;185:317-35.
21. Veremeichik GN, Bulgakov VP, Shkryl YN, Silantieva SA, Makhazen DS, Tchernoded GK, et al. Activation of anthraquinone biosynthesis in longcultured callus culture of Rubia cordifolia transformed with the rolA plant oncogene. J Biotechnol. 2019;306:38-46.

22. Piwowarczyk B, Tokarz K, Muszyńska E, Makowski W, Jędrzejczyk R, Gajewski Z, et al. The acclimatization strategies of kidney vetch (Anthyllis vulneraria L.) to Pb toxicity. Environ Sci Pollut Res. 2018:25:19739-52.

23. Franklin G, Conceiçăo LFR, Kombrink E, Dias ACP. Xanthone biosynthesis in Hypericum perforatum cells provides antioxidant and antimicrobial protection upon biotic stress. Phytochemistry. 2009;70:60-8.

24. Honglin H, Farhan U, Dao-Xiu Z, Ming Y, Yu Z. Mechanisms of ROS regulation of plant development and stress responses. Front Plant Sci. 2019;10:800. https://doi.org/10.3389/fpls.2019.00800.

25. Trovato M, Mattioli R, Costantino P. From A. rhizogenes RolD to Plant P5CS: exploiting proline to control plant development. Plants. 2018;7:108. https://doi.org/10.3390/plants7040108.

26. Sawahel WA, Hassan AH. Generation of transgenic wheat plants producing high levels of the osmoprotectant proline. Biotechnol Lett. 2002;24:721-5.

27. Lattanzio V, Caretto S, Linsalata V, Colella G, Mita G. Signal transduction in artichoke [Cynara cardunculus L. subsp. scolymus (L.) Hayek] callus and cell suspension cultures under nutritional stress. Plant Physiol Biochem. 2018;127:97-103.

28. Cheynier V, Comte G, Davies KM, Lattanzio V, Martens S. Plant phenolics: recent advances on their biosynthesis, genetics, and ecophysiology. Plant Physiol Biochem. 2013;72:1-20.

29. Shkry YN, Veremeichik GN, Bulgakov VP, Gorpenchenko TY, Aminin DL, Zhuravlev YN. Decreased ROS level and activation of antioxidant gene expression in Agrobacterium rhizogenes pRiA4-transformed calli of Rubia cordifolia. Planta. 2010;232:1023-32.

30. Kohsari S, Rezayian M, Niknam V, Mirmasoumi M. Antioxidative enzymes activities and accumulation of steroids in hairy roots of Trigonella. Physiol Mol Biol Plants. 2020;26(2):281-8.

31. Shkryl YN, Veremeichik GN, Bulgakov VP, Avramenko TV, Günter EA, Ovodov YS, et al. The production of class III plant peroxidases in transgenic callus cultures transformed with the rolB gene of Agrobacterium rhizogenes. J Biotechnol. 2013;168:64-70.

32. Alscher Grene RG, Erturk N, Heath LS. Role of superoxide dismutases (SODs) in controlling oxidative stress in plants. J Exp Bot. 2002;372(53):1331-41.

33. Foyer $\mathrm{CH}$, Noctor $\mathrm{G}$. Redox homeostasis and antioxidant signaling: a metabolic interface between stress perception and physiological responses. Plant Cell. 2005;17:1866-75.

34. Wiszniewska A, Muszyńska E, Kołton A, Kamińska I, Hanus-Fajerska E. In vitro acclimation to prolonged metallic stress is associated with modulation of antioxidant responses in a woody shrub Daphne jasminea. Plant Cell Tissue Organ Cult. 2019;139:339-57.

35. Ghimire BK, Thiruvengadam M, Chung IM. Identification of elicitors enhances the polyphenolic compounds and pharmacological potential in hairy root cultures of Aster scaber. S Afr J Bot. 2019;125:92-101.

36. Ansari MA, Chung IM, Rajakumar G, Alzohairy MA, Almatroudi A, Khanna VG, et al. Evaluation of polyphenolic compounds and pharmacological activities in hairy root cultures of Ligularia fischeri Turcz. f. spiciformis (Nakai). Molecules. 2019;24:1586. https://doi.org/10.3390/ molecules 24081586.

37. Kim HU. Lipid metabolism in plants. Plants. 2020;9(7):871. https://doi. org/10.3390/plants9070871.

38. Tokarz KM, Wesołowski W, Tokarz B, Makowski W, Wysocka A, Jędrzejczyk RJ, et al. Stem photosynthesis-a key element of grass pea (Lathyrus sativus L.) acclimatisation to salinity. Int J Mol Sci. 2021;22:68. https://doi.org/10.3390/ijms22020685.

39. Upchurch RG. Fatty acid unsaturation, mobilization, and regulation in the response of plants to stress. Biotechnol Lett. 2008;30:967-77.

40. Walley JW, Kliebenstein DJ, Bostock RM, Dehesh K. Fatty acids and early detection of pathogens. Curr Opin Plant Biol. 2013;16:520-6.

41. Fladung $M$, Gieffers W. Resistance reactions of leaves and tubers of rolC transgenic tetraploid potato to bacterial and fungal pathogens. Correlation with sugar, starch and chlorophyll content. Physiol Mol Plant Path. 1993;42(2):123-32. 
42. Grishchenko OV, Kiselev KV, Tchernoded GK, Fedoreyev SA, Veselova MV, Bulgakov VP, et al. Ro/B gene-induced production of isoflavonoids in transformed Maackia amurensis cells. Appl Microbiol Biotechnol. 2016;100:7479-89.

43. Sakr S, Wang M, Dédaldéchamp F, Perez-Garcia M-D, Ogé L, Hamama L, et al. The sugar-signaling hub: overview of regulators and interaction with the hormonal and metabolic network. Int J Mol Sci. 2018;19:2506. https://doi.org/10.3390/ijms19092506.

44. Couée I, Sulmon C, Gouesbet G, El Amrani A. Involvement of soluble sugars in reactive oxygen species balance and responses to oxidative stress in plants. J Exp Bot. 2006;57(3):449-59.

45. Murashige T, Skoog F. A revised medium for rapid growth and bioassays with tobacco tissue cultures. Physiol Plant. 1962;15:473-97.

46. Dhindsa RH, Plumb-Dhindsa R, Thorpe TA. Leaf senescence correlated with increased level of membrane permeability, lipid peroxidation and decreased level of SOD and CAT. J Exp Bot. 1981;32:93-101.

47. Piwowarczyk B, Wójtowicz T, Makowski W, Roman JJ, Tokarz KM. What is the difference between response of grass pea (Lathyrus sativus L.) to salinity and drought stress? - Physiological study. Agronomy. 2020:10(6):833. https://doi.org/10.3390/agronomy10060833.

48. Bates LS, Waldern RP, Teare ID. Rapid determination of free proline from water stress studies. Plant Soil. 1973;39:205-7.

49. Makowski W, Tokarz B, Banasiuk R, Królicka A, Dziurka M, Wojciechowska R, et al. Is a blue-red light a good elicitor of phenolic compounds in the family Droseraceae? A comparative study. J Photochem Photobiol B Biol 2019;201:111679 (doi: https://doi.org/10.1016/j. jphotobiol.2019.111679)

50. Bradford MM. A rapid and sensitive method for the quantitation of microgram quantities of protein utilizing the principle of protein-dye binding. Anal Biochem. 1976;72:248-54.

51. Aebi H. Catalase in vitro. Methods Enzymol. 1984;105:121-6.

52. Tokarz K, Makowski W, Banasiuk R, Królicka A, Piwowarczyk B. Response of Dionaea muscipula J. Ellis to light stress in in vitro: physiological study. Plant Cell Tissue Organ Cult. 2018;134(1):65-77.

53. Lück H. Methoden der enzymatischen analyse. Weinheim: Verlag Chemie GmbH; 1962. p. 895-7.

54. Hwang SY, Lin HW, Chern RH, Lo HF, Li L. Reduced susceptibility to waterlogging together with high-light stress is related to increases in superoxide dismutase and catalase activities in sweet potato. Plant Growth Regul. 1999;27:167-72.

55. Tokarz KM, Makowski W, Tokarz B, Hanula M, Sitek E, Muszyńska E, et al. Can Ceylon leadwort (Plumbago zeylanica L.) acclimate to lead toxicity? - Studies of photosynthetic apparatus efficiency. Int J Mol Sci. 2020;21:1866. https://doi.org/10.3390/ijms21051866.

56. Wellburn AR. The spectral determination of chlorophylls a and b, as well as total carotenoids, using various solvents with spectrophotometers of different resolution. J Plant Physiol. 1994;144:307-13.

57. Queval G, Noctor G. A plate reader method for the measurement of NAD, NADP, glutathione, and ascorbate in tissue extracts: application to redox profiling during Arabidopsis rosette development. Anal Biochem. 2007:363:58-69.

58. Sułkowska-Ziaja K, Maślanka A, Szewczyk A, Muszyńska B. Physiologically active compounds in four species of Phellinus. Nat Prod Commun. 2017;12:363-6.

59. Szopa A, Dziurka M, Granica S, Klimek-Szczykutowicz M, Kubica P, Warzecha A, et al. Schisandra rubriflora plant material and in vitro microshoot cultures as rich sources of natural phenolic antioxidants. Antioxidants. 2020;9(6):488. https://doi.org/10.3390/antiox9060488.

\section{Publisher's Note}

Springer Nature remains neutral with regard to jurisdictional claims in published maps and institutional affiliations.

Ready to submit your research? Choose BMC and benefit from:

- fast, convenient online submission

- thorough peer review by experienced researchers in your field

- rapid publication on acceptance

- support for research data, including large and complex data types

- gold Open Access which fosters wider collaboration and increased citations

- maximum visibility for your research: over $100 \mathrm{M}$ website views per year

At BMC, research is always in progress.

Learn more biomedcentral.com/submissions 